\title{
Segmental Approach to Lung Volume Reduction Therapy for Emphysema Patients
}

\author{
Sourish Bandyopadhyay ${ }^{a}$ Erik Henne $^{a} \quad$ Avina Gupta $^{a}$ Robert Barry ${ }^{a}$ \\ Greg Snell $^{b}$ Charlie Strange ${ }^{c}$ Felix J.F. Herth ${ }^{d}$ \\ a Uptake Medical, Tustin, Calif., USA; ${ }^{b}$ Allergy Immunology and Respiratory Medicine, The Alfred Hospital, \\ Melbourne, Vic., Australia; ' $D$ Division of Pulmonary and Critical Care Medicine, Medical University of South Carolina, \\ Charleston, S.C., USA; ${ }^{d}$ Department of Pneumology and Respiratory Critical Care Medicine, Thoraxklinik, University \\ of Heidelberg, Heidelberg, Germany
}

\section{Key Words}

Ablation - Bronchoscopic lung volume reduction . Heterogeneity · Lung volume reduction · Segmental approach - Tissue/air ratio - Vapor

\section{Abstract}

Emphysema is often distributed heterogeneously throughout the lungs, even at the segmental level. It is important for interventional lung volume reduction therapies to target and treat the most diseased regions of the lung while preserving the less diseased functional regions. Identification and determination of the severity of emphysema can be done using the various quantification measures reviewed in this article. However, all of these measures are similar in what they quantify and are equally good indicators of emphysema. The tissue/air ratio was chosen for our purposes. Software capable of quantifying emphysema severity at the segmental level exists, and can be utilized to identify the most diseased segments while following anatomical boundaries. The segmental heterogeneity index is a new measure being introduced to help quantify differences in emphysema severity at the segmental level. The goal of segmental targeting is to improve efficacy and safety outcomes of va- por ablation patients. The Sequential Staged Treatment of Emphysema with Upper Lobe Predominance (STEP-UP, NCT01719263) trial is currently enrolling patients with upper lobe heterogeneous emphysema using these techniques.

(c) 2014 S. Karger AG, Basel

\section{Introduction}

Emphysema is defined as 'the presence of permanent enlargement of the airspaces distal to the terminal bronchioles, accompanied by destruction of their walls and without obvious fibrosis' [1]. Emphysema is typically defined in anatomical terms; therefore, lung radiography provides the clearest evidence of its presence. High resolution computed tomography (CT) scans have greater sensitivity and specificity than chest radiographs and provide detailed anatomical information to help identify areas of emphysema within the lung. The precise identification of emphysema at the segmental level will allow bronchoscopic lung volume reduction (BLVR) technologies to selectively target and treat the most diseased segments of the lungs.

\begin{tabular}{ll}
\hline KARGER 125: & $\begin{array}{l}\text { (1) 2014 S. Karger AG, Basel } \\
0025-7931 / 14 / 0891-0076 \$ 39.50 / 0 \quad \text { Karger }\end{array}$ \\
$\begin{array}{l}\text { E-Mail karger@karger.com } \\
\text { www.karger.com/res }\end{array}$ & $\begin{array}{l}\text { This is an Open Access article licensed under the terms of the } \\
\text { Creative Commons Attribution-NonCommercial 3.0 Un- } \\
\text { ported license (CC BY-NC) (www.karger.com/OA-license), } \\
\text { applicable to the online version of the article only. Distribu- } \\
\text { tion permitted for non-commercial purposes only. }\end{array}$
\end{tabular}

Sourish Bandyopadhyay

Uptake Medical

1173 Warner Avenue

Tustin, CA 92780 (USA)

E-Mail sourish@uptakemedical.com 


\section{Qualitative Emphysema Characterization from Imaging}

Adequate phenotyping of chronic obstructive pulmonary disease (COPD) requires measurement of the extent and severity of emphysema, physiologic measurements, and patient-reported outcomes. A variety of physiologic measurements, including forced expiratory volume in $1 \mathrm{~s}$, diffusing capacity of carbon monoxide, lung volumes, and exercise capacity, are useful in determining the severity of lung disease [2]. Perfusion scans are also useful in characterizing the severity of emphysema. However, these measurements are not a reliable indicator of hyperinflation, which is the target for most lung volume reduction (LVR) therapies.

When observing chest radiographs, physicians attempt to identify the following emphysema characteristics: large hyperinflated lungs, low set diaphragms, hyperlucent lung fields, increased apicoposterior diameter, vertical heart, and radiographic bullae [3]. Although radiographs provide substantial information about the lungs, they lack sufficient resolution to accurately diagnose emphysema.

CT scans provide a much higher resolution and detail of the lung anatomy. This increased resolution allows physicians to assess and diagnose emphysema as precisely as it would have been possible on excised lung tissue [4]. Using CT scans, physicians are able to visually locate and characterize the specific type of obstructive disease. Emphysema can be reliably identified by observing small air pockets or low density tissue surrounded by more normal lung regions [5]. Compared with pathological examination for emphysema, these visual assessments have demonstrated a good correlation [6]. However, visual assessments are time consuming and limited by high interobserver variability and lack of sensitivity to early disease [6].

\section{Quantitative Emphysema Characterization from Imaging}

The movement towards computerized quantification techniques was initiated by radiology groups who confirmed that emphysema morphology can be accurately observed on a CT scan. Technology that allowed thin slice acquisition (now standard on all CT scanners) allowed visualization of terminal and respiratory bronchioles $[7,8]$. Distal focal areas of low attenuation can be easily identified using computer algorithms which quan- tify the areas of low attenuation based on density index thresholds. Various measures have been developed based on computerized techniques that are summarized in table 1 .

Computerized approaches to emphysema quantification were primarily developed with the intention to more accurately and objectively diagnose overall emphysema within the lungs. However, as interventional emphysema therapies such as BLVR are becoming more prevalent, more accurate methods of characterizing emphysema at the segmental level are needed. This paper will identify the need for BLVR technologies to reduce lung volume segmentally and demonstrate techniques to identify and distinguish the severity of emphysema at the segmental level.

\section{Current State of LVR Technology}

LVR techniques, including surgery, valves, vapor, and sealants, attempt to target the regions of the lung with the greatest extent of emphysema. In each LVR technique, the lungs are evaluated for emphysema at the lobar level with the help of CT scans. For BLVR, endobronchial valves (Zephyr ${ }^{\circledR}$ by Pulmonx or IBV by Spiration), for example, are placed in segmental airways and work best when deployed to occlude an entire lobe. The valves achieve LVR by restricting air supply to the lobe. Valves are an effective method of reducing lung volume in patients without interlobar collateral ventilation [9].

Vapor ablation LVR technology, however, is effective in the presence of both interlobar and intralobar collateral ventilation, because vapor ablation creates a permanent volume reduction which is independent of collateral gas channels. The ability of LVR procedures to accurately target emphysema at a lobar level has been a significant advancement, but treating at the lobar level may lead to the unnecessary reduction of segments with functional tissue. Therefore, the ability of vapor ablation LVR technology to target diseased regions at the segmental level could offer more optimal treatment and further benefit to the patient.

\section{Heterogeneity: Comparing the Severity of Emphysema Disease States}

Emphysematous destruction and gas trapping occurs unevenly throughout the lung leading to heterogeneous emphysema. The National Emphysema Treatment Trial 
Table 1. Emphysema quantification measures

\begin{tabular}{|c|c|c|c|c|c|}
\hline & \multicolumn{5}{|l|}{ Quantification measures } \\
\hline Brief description & $\begin{array}{l}\text { Percentage of voxels } \\
\text { which are below a } \\
\text { designated density } \\
\text { threshold ( }-950 \mathrm{HU} \\
\text { is the typical } \\
\text { threshold) }\end{array}$ & $\begin{array}{l}\text { Measure of low } \\
\text { attenuation lesion } \\
\text { size and number of } \\
\text { lesions }\end{array}$ & $\begin{array}{l}\text { Hounsfield density } \\
\text { below which } 15 \% \text { of } \\
\text { all voxels are } \\
\text { distributed }\end{array}$ & $\begin{array}{l}\text { Average of the individual } \\
\text { voxel densities in a given } \\
\text { region of the lung }\end{array}$ & $\begin{array}{l}\text { Voxels are divided into air } \\
\text { and tissue based on density } \\
\text { values Tissue measurements } \\
\text { are divided by the air } \\
\text { measurements for each } \\
\text { region to determine the ratio }\end{array}$ \\
\hline Units of measure & $\%$ & Slope & $\mathrm{HU}$ & $\mathrm{HU}$ & $\%$ \\
\hline Range of values & $0-100$ & 0 to infinity & 0 to $-1,000$ & 0 to $-1,000$ & $0-100$ \\
\hline $\begin{array}{l}\text { Interpretation } \\
\text { of values }\end{array}$ & $\begin{array}{l}\text { High percentage } \\
\text { means more areas of } \\
\text { low attenuation and } \\
\text { more severe disease }\end{array}$ & $\begin{array}{l}\text { A flatter slope } \\
\text { indicates larger } \\
\text { lesions, which } \\
\text { corresponds to more } \\
\text { severe disease }\end{array}$ & $\begin{array}{l}\text { The lower the } 15 \text { th } \\
\text { percentile density } \\
\text { point the higher the } \\
\text { severity of the } \\
\text { disease }\end{array}$ & $\begin{array}{l}\text { The lower the MLD the } \\
\text { higher the severity of the } \\
\text { disease }\end{array}$ & $\begin{array}{l}\text { The lower the TAR the higher } \\
\text { the severity of disease }\end{array}$ \\
\hline Strengths & $\begin{array}{l}\text { Widely used measure. } \\
\text { Good correlation with } \\
\text { emphysema PFT } \\
\text { (FEV } \% \text { of predicted) } \\
\text { measures }\end{array}$ & $\begin{array}{l}\text { Good correlation } \\
\text { with LAA\% and } \\
\text { visual scores } \\
\text { can help distinguish } \\
\text { emphysema from } \\
\text { small airway disease }\end{array}$ & $\begin{array}{l}\text { Wide range of } \\
\text { densities evaluated } \\
\text { using this measure }\end{array}$ & $\begin{array}{l}\text { Density measure, accounts } \\
\text { for both tissue and air }\end{array}$ & $\begin{array}{l}\text { Tissue and air volumes are a } \\
\text { more relatable and } \\
\text { understandable measure }\end{array}$ \\
\hline
\end{tabular}

$\mathrm{AWUV}=$ Airspace wall per unit lung volume; $\mathrm{FEV}_{1}=$ forced expiratory volume in $1 \mathrm{~s} ; \mathrm{HU}=$ Hounsfield unit; PFT = pulmonary function test; VC = vital capacity; $\mathrm{LAC}=$ low attenuation cluster; $\mathrm{MLD}=$ mean lung density.

(NETT), which evaluated 1,218 patients for LVR surgery (LVRS), measured heterogeneity based on visual scoring (fig. 1). The heterogeneity in disease distribution was shown to correlate with LVRS outcome variables. Targeting unevenly distributed disease is a part of the method of action of LVRS. LVRS therapies are successful by reducing hyperinflation, which results in the decompression of the surrounding functional lung regions. One important conclusion of NETT was that participants with upper lobe emphysema who underwent LVRS exhibited better outcomes than other cohorts [10]. Based on this observation, subsequent LVR techniques have used various forms of heterogeneity measurement to achieve maximal benefit and reduction at the least cost of functional tissue [11].

\section{Heterogeneity of Emphysema Using Computerized Quantitative Measures}

Heterogeneity of emphysema has typically been established through visual scoring as in NETT, but visual scoring is subjective and open to interobserver variability, especially at the segmental level. With the help of accurate quantitative techniques, it is possible to reliably and precisely establish the severity of emphysema in a given location with respect to the rest of the lungs. Chae et al. [12] described a quantitative technique where the slice-specific low attenuation area percentage (LAA\%) was plotted against the location. The slope of the plot curves indicated the heterogeneity of disease between various locations in the lungs (fig. 2). An evaluation of 59 patients concluded that this technique of measuring heterogeneity was comparable to the visual assessment techniques. 


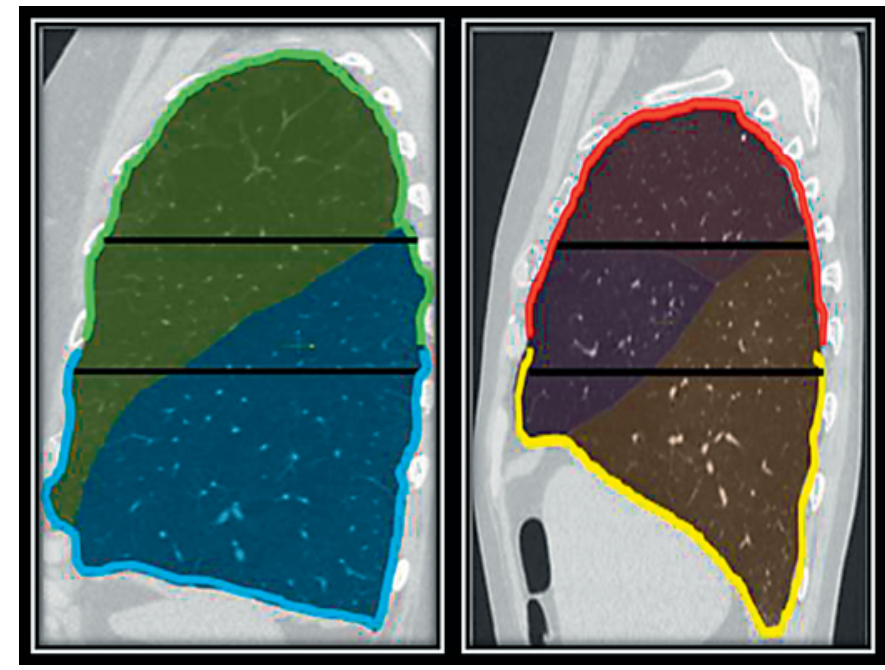

Fig. 1. NETT method of calculating heterogeneity was done along arbitrary boundaries or 'lung sectors' of lower verses upper sectors. For each sector the density of the lower field was compared to the density of the upper field [16]. On each sector, the comparison includes tissue from the neighboring lobe. LVR treatments follow anatomical boundaries, therefore this visual method of evaluating heterogeneity is less accurate than computerized methods which can follow anatomical boundaries.

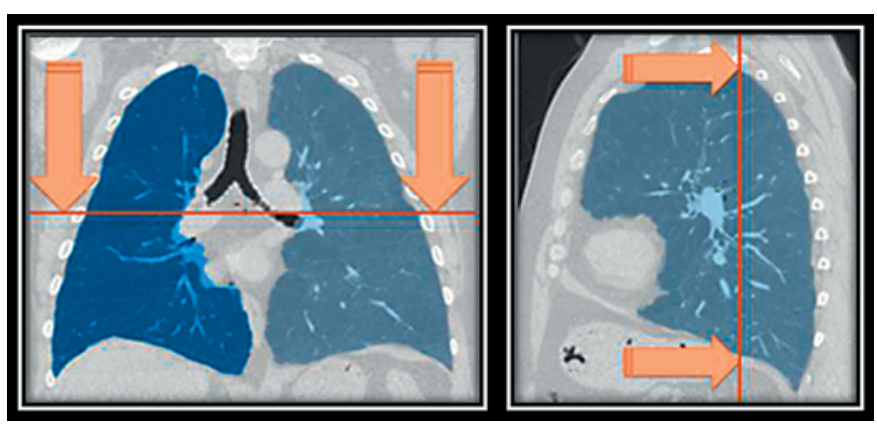

Fig. 2. Method used by Chae et al. [12] to calculate heterogeneity was done along planar slices in a particular direction as shown. LVR treatments follow anatomical boundaries, therefore this method of calculating heterogeneity is not ideal for characterizing disease distribution.

The technique identified by Chae et al. [12] is useful in identifying disease heterogeneity; however, it does not fulfill the need of modern LVR technologies to identify and treat at the segmental level. The technique does not follow the anatomical boundaries of the sublobar segments or the lobar fissure boundaries, making it less useful for BLVR therapies.

Segmental Approach to LVR Therapy
Software has been developed in recent years to make quantitative measurements of the lung from high resolution CT scans. One such software, VIDA A pollo software, developed by VIDA Diagnostics (Iowa City, Iowa, USA), is capable of analyzing high resolution CT scans to determine airway measurements, regional lung volumes, and regional lung masses. This software is capable of identifying lung parenchymal volumes and densities at the lung, lobar, and segmental levels (fig. 3). This software has been used to quantify human emphysema by groups such as Gietema et al. [13]. Henne et al. [14] measured the accuracy of the software at the segmental level between lung density and ex vivo lung preparations and found strong concordance. The ability to quantify emphysema along anatomical boundaries at the segmental level has not been possible previously.

\section{Heterogeneity along Anatomical Boundaries at Segmental Level}

Given the capabilities of modern software to quantify emphysema at both the lobar and segmental level, it is now possible to determine differences in emphysema severity between two anatomical regions along precise boundaries. Differences in the severity of emphysema between two regions can be determined using a comparison index called the heterogeneity index (HI). In general, the $\mathrm{HI}$ equation can be defined as follows:

Equation 1: general HI calculation

$$
\mathrm{HI}=\frac{\text { quantitative measure of region } \mathrm{A}}{\text { quantitative measure of region } \mathrm{B}} .
$$

The general HI was first used in the VENT (NCT00129584) study and was defined as the ratio of the densities of the lower lobe to the upper lobe similar to NETT [15]. For the Sequential Staged Treatment of Emphysema with Upper Lobe Predominance (STEPUP, NCT01719263) trial, the HI is being measured at the segmental level. Also, the STEP-UP trial is using the tissue/air ratio (TAR) measure to quantify emphysema. The upper lobe segments are not equally diseased, and, therefore, treating at the lobar level may lead to unnecessary reduction of functional tissue. Utilizing the segmental approach will allow physicians to distinguish the severity of disease between the upper lobe segments. The difference in the severity of the disease between an upper lobe segment and the full lower lobe is being defined by equation 2 . 


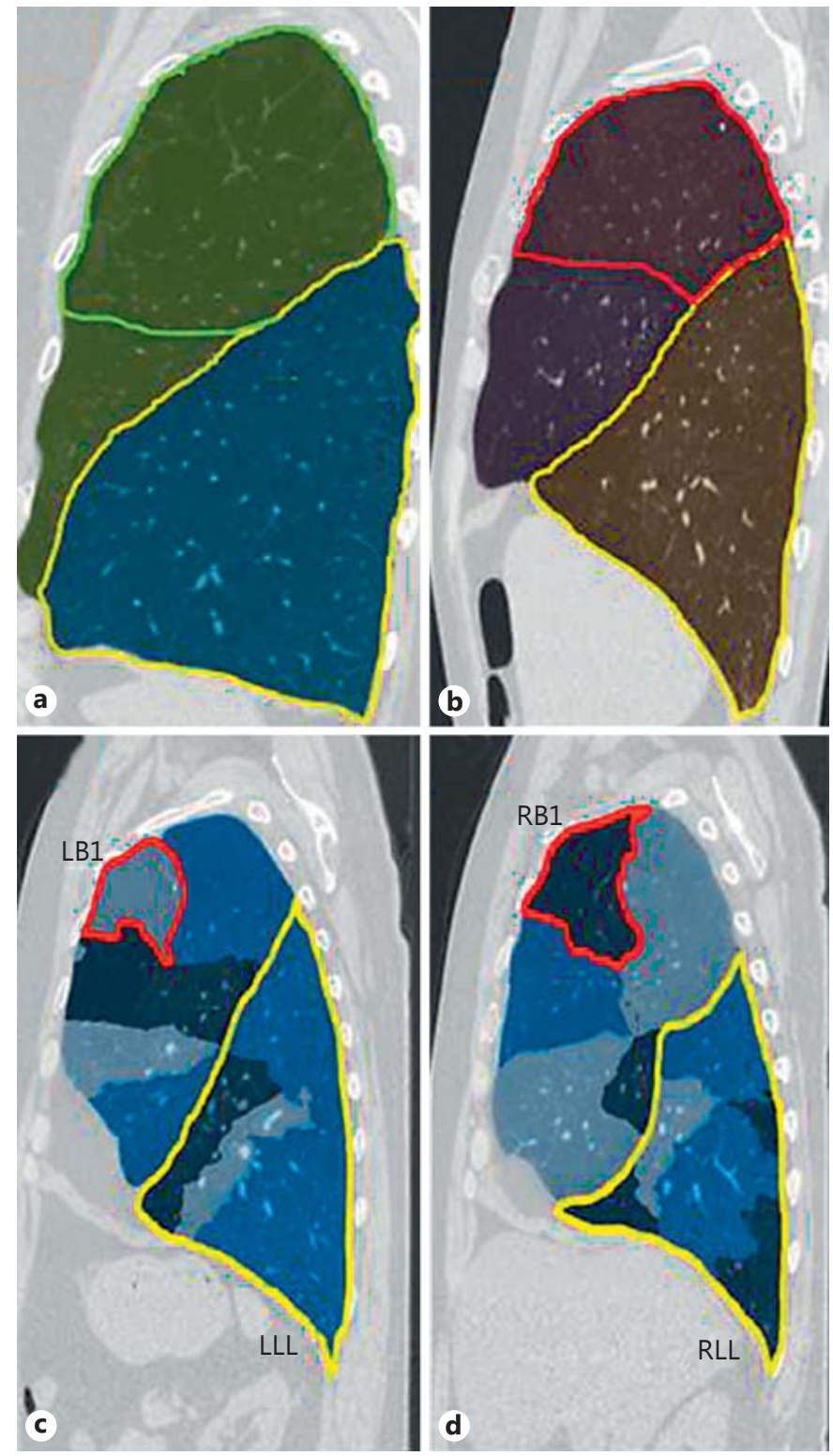

Fig. 3. The HI using the VIDA Apollo software is calculated along anatomical boundaries. For the left lung (a), the TAR of the left lower lobe (yellow) is divided by the TAR of the upper lobe (green) without the lingula. For the right lung (b), the TAR of the right lower lobe (yellow) is divided by the TAR of the right upper lobe (red). The HI using the VIDA Apollo software can be calculated along anatomical boundaries at the segmental level. The segmental anatomical boundaries are depicted above in various shades of blue. RB1 and LB1 segment sublobar regions are marked by the red border and the right (RLL) and left lower lobes (LLL) are marked by the yellow border $(\mathbf{c}, \mathbf{d})$.
Table 2. TAR and HI calculation of an example patient

\begin{tabular}{lrl}
\hline Lung region & TAR, \% & HI \\
\hline LB1 & 8.2 & 1.6 \\
LB2 & 10.5 & 1.3 \\
LB3 & 6.4 & 2.1 \\
Left lower lobe TAR & 13.0 & \\
RB1 & 7.9 & 1.8 \\
RB2 & 11.5 & 1.2 \\
RB3 & 12.9 & 1.1 \\
Right lower lobe TAR & 14.0 & \\
\hline
\end{tabular}

Equation 2: HI calculation at segmental level

Segmental HI $=\frac{\text { lower lobe TAR }}{\text { segment X TAR }}$,

where $\mathrm{X}$ represents a segment of the upper lungs (i.e. RB1).

The upper lobe segments and lower lobe regions can be compared against each other using equation 2 . An interpretation of the values which can be generated using these heterogeneity equations are as follows. A HI value of 1.0 represents a lung with similar upper lobe segment and lower lobe TAR or lung density. The severity of emphysema in the upper lobe segment and lower lobes is the same when $\mathrm{HI}$ is 1.0. A HI of 1.0 is indicative of a lung which has homogeneously distributed emphysema disease between the two comparison regions. A HI value less than 1.0 is indicative of a lung with emphysema predominant in the lower lobes. Similarly, a HI value greater than 1.0 is a lung with more disease in the upper lobe segment than in the lower lobe.

An example patient has been evaluated using the VIDA software to demonstrate the lobar and segmental emphysema measurement capabilities. The TAR measure was calculated at the various levels of the lung. Using the segmental TAR values, the heterogeneity of emphysema was calculated. Each segment in both left and right lung varied in the severity of emphysema as characterized by the associated segment TAR and HI values listed in table 2. In this example patient, segment RB1 was observed to have more emphysema than segments RB2 and $\mathrm{RB} 3$ in the right upper lobe and segment LB3 had more emphysema than segments LB1 and LB2 in the left upper lobe. Therefore, in this example, a capable reduction technology such as vapor ablation should target and treat the most diseased segments, which are RB1 and LB3. 


\section{Conclusion}

The techniques of characterizing emphysema have progressed from basic pulmonary function tests and low quality radiographic visual assessments to computerized measures from high resolution CT scans of the patient lung. We have reviewed the many different ways to quantify and measure the severity of emphysema using CT scans, such as LAA\%, low attenuation cluster, 15th percent, mean lung density, and TAR. The proposed method to characterize disease heterogeneity along anatomical boundaries at the segmental level will help to meet the needs of BLVR therapy to more optimally deliver volume reduction treatments to the most diseased regions of the lung. Currently, targeting at the segmental level is possible with vapor ablation. The goal of targeting treatments to the most diseased segments is to improve efficacy and safety of outcomes of vapor ablation patients. The STEP-UP trial is currently evaluating the proposed segmental approach using TAR and a segmental HI to target bronchoscopic vapor LVR. If lung volume is successfully reduced using this segmental approach, it may be possible to target diseased segments throughout the entire lung in the near future.

\section{References}

1 Standards for the diagnosis and care of patients with chronic obstructive pulmonary disease. Am J Respir Crit Care Med 1995; 152(5 pt 2):S77-S121.

2 Gildea T: Pulmonary function testing. Cleveland, Cleveland Clinic, http://www. clevelandclinicmeded.com/medicalpubs/ diseasemanagement/pulmonary/pulmonaryfunction-testing/.

3 Chandrasekhar A: Chronic obstructive lung disease (COPD)/emphysema. http:// www.stritch.luc.edu/lumen/MedEd/Radio/ curriculum/Medicine/emphysema.htm.

4 Coxson HO, Rogers RM: Quantitative computed tomography of chronic obstructive pulmonary disease. Acad Radiol 2005; 12:14571463.

5 Washko GR: Diagnostic imaging in COPD. Semin Respir Crit Care Med 2010;31:276285.

6 Uppaluri R, Mitsa T, Sonka M, et al: Quantification of pulmonary emphysema from lung computed tomography images. Am J Respir Crit Care Med 1997;156:248-254.

7 Murata K: Centrilobular lesions of the lung: demonstration by high-resolution CT and pathologic correlation. Radiology 1986;161: 641-645.

8 Stern EJ, Frank MS: CT of the lung in patients with pulmonary emphysema: diagnosis, quantification, and correlation with pathologic and physiologic findings. AJR Am J Roentgenol 1994;162:791-798.
9 Oliveira HG, Rambo RR, Macedo-Neto AV, et al: Fissure integrity as a non-invasive method to predict volume reduction in endobronchial valve treatment of emphysema. http:// www.atsjournals.org/doi/abs/10.1164/ajrccm-conference.2013.187.1_MeetingAbstracts.A3580.

10 US Department of Health and Human Services: National Emphysema Treatment Trial (NETT): Evaluation of Lung Volume Reduction Surgery for Emphysema. Bethesda, National Health National Heart, Lung, and Blood Institute, 2003, http://www.nhlbi.nih. gov/health/prof/lung/nett/lvrsweb.htm.

$\rightarrow 11$ Russi EW, Bloch KE, Weder W: Functional and morphological heterogeneity of emphysema and its implication for selection of patients for lung volume reduction surgery. Eur Respir J 1999;14:230-236.

12 Chae EJ, Seo JB, Song JW, Kim N, Park BW, Lee YK, Oh YM, Lee SD, Lim SY: Slope of emphysema index: an objective descriptor of regional heterogeneity of emphysema and an independent determinant of pulmonary function. AJR Am J Roentgenol 2010; 194:W248-W255.

13 Gietema HA, Müller NL, Fauerbach PV, et al: Quantifying the extent of emphysema: factors associated with radiologists' estimations and quantitative indices of emphysema severity using the ECLIPSE cohort. Acad Radiol 2011; 18:661-671.
14 Henne E, Anderson JC, Lowe N, et al: Comparison of human lung tissue mass measurements from ex vivo lungs and high resolution CT software analysis. BMC Pulm Med 2012; 12:18

15 Vent Pivotal Trial Clinical Summary. http:// www.fda.gov/ohrms/dockets/ac/08/ briefing/2008-4405b1-06-Clinical\%20Summary.pdf.

16 National Emphysema Treatment Trial Research Group: Patients at high risk of death after lung-volume-reduction surgery. $\mathrm{N}$ Engl J Med 2001;345:1075-1083.

17 Gould GA, MacNee W, McLean A, et al: CT Measurements of lung density in life can quantitate distal airspace enlargement - an essential defining feature of human emphysema. Am Rev Respir Dis 1988;137:380-392.

18 Zach JA, Tschirren J, Nambu A, et al: Correlations of CT low attenuation clusters with visually assessed extent and pattern of emphysema. http://www.atsjournals.org/doi/ abs/10.1164/ajrccm-conference.2013.187.1_ MeetingAbstracts.A3727.

19 Shaker SB, Maltbaek N, Brand P, et al: Quantitative computed tomography and aerosol morphometry in COPD and al-antitrypsin deficiency. Eur Respir J 2005;25:23-30.

20 Heremans A, Verschakelen JA, Van fraeyenhoven L, et al: Measurement of lung density by means of quantitative CT scanning. Chest 1992;102:805-811. 